\title{
Risk Management Effectiveness of Oil And Gas Pipeline Construction in Java Island - Indonesia
}

\author{
I Putu Artama Wiguna ${ }^{1}$, Nadjadji Anwar ${ }^{2}$, Amien Widodo ${ }^{3}$, Nova Nevila Rodhi ${ }^{4}$ \\ Institut Teknologi Sepuluh Nopember Surabaya. Indonesia. ${ }^{1,2,3,4}$ \\ email: artama.wiguna@gmail.com
}

\begin{abstract}
One of the important oil and gas industry is oil and gas pipeline which serves to support the gas transmission and distribution process. The oil and gas pipeline routes are so long and cross through some areas that certainly raises the risk of adversely affecting the environment, especially for the pipeline located in a densely populated area, where at certain conditions, the pipe can leak and may cause the explosion. Many researches have been conducted concerning on the project pipeline risks which concluded that the oil and gas pipeline project has very complex risks. In addition, the oil and gas project may cause a potential disaster. Currently oil and gas companies have been implementing risk management to minimize the negative impacts, but the negative impacts are still occurred. This is due to ineffective risk management implementation. This study aims to analyze the effectiveness of risk management system for oil and gas pipeline project in Java Island. Based on a deep study literature review, it shows that the effectiveness of risk management can be achieved by taking account into environmental, social and economic factors that are the pillars of sustainable development system. The potential disaster was also to be considered as an addition factor. Therefore, four identified factors were analyzed using Analytical Hierarchy Process (AHP) method. Data were obtained using questionnaire which were distributed to oil and gas project team. It is found that the most factors to be considered was social aspect $(40 \%)$ and the other factors contributed $31 \%$ for disaster, $15 \%$ for economic, $14 \%$ for environment. Those factors should be taken account in the design stage as the most priority.
\end{abstract}

Keywords—Risk Assessment, Analytical Hierarchy Process (AHP), Sustainable Development

\section{INTRODUCTION}

$\mathrm{I}_{\mathrm{n}}$ the oil and gas industry, there are several series of supporting activities, one of which is the transportation activities, which the current operations are carried out using pipelines. Transport by pipeline is considered safer, more effective and efficient than other transportation methods. However, transportation methods with pipelines also have risks that must be managed so that the objectives can be achieved in accordance with the expected plan [1]. As other activities constitute a series of projects within the oil and gas industry, pipeline projects within the oil and gas industry also have a potentially hazard [2]. Currently the company engaged in the pipeline has developed and adopted various methods to minimize and control the existing threats, but so far the application of risk management by oil and gas companies is used as a method that is preventive [2]. In addition, risk management tends to be used at the operational stage and uses the Risk Based Inspection (RBI) reference.

The risks contained in the oil and gas pipeline project can certainly be anticipated with risk management applications, but if risk management has been applied and still has a negative impact, it is because the risk management application is not systematic and ineffective. Therefore, it is necessary to develop a concept of risk management that can build an effective risk management system [3]. In ISO 31000: 2009, it is mentioned that the effectiveness of risk management can be achieved by considering 11 (eleven) risk management principles. Basically, the risk management principle shows that risk management must be done with regard to all aspects of the project management field so that risk management can help achieve the desired target [4].

Since pipeline projects are hazardous and potentially catastrophic, it is imperative that they no longer be subjected to preventive matters, but should be in coping activities [5]. One effort to undertake countermeasures can be done by taking into account the concept of sustainable development in activities to be undertaken [6]. As for the pipeline operating system, it is currently used with reference to the Pipeline Integration Management System (PIMS) [7]. Based on the 
description, this paper aims to analyze an effective risk management system for oil and gas pipelines project in Java island.

The effectiveness of risk management is conducted based on the review literature on relevant previous research results. The results of the literature review mentioned that, in general, risk management applied by some oil and gas companies more emphasis on risk management HSE (Health, Safety, and Environment) [8]. In ISO 31000: 2009, it is mentioned that the effectiveness of risk management can be achieved by considering 11 (eleven) risk management principles. Basically, the risk management principle shows that risk management must be done with regard to all aspects of the project management field so that risk management can help achieve the desired target.

Currently, in addition to the principles that must be adhered to also there is a concept that must be considered and taken into account in every activity. It is a concept of sustainable development [6]. Sustainable development is a development concept that aims to provide a better quality of life for all people, both at present and in future generations [9]. Thus, construction project risk management must also be carried out taking into consideration the concept of sustainable development. So that the planned project can achieve a sustainable construction project and can support sustainable development targets [10].

To achieve sustainable development, construction project risk management must be carried out with respect to the objectives of Sustainable Development Goals, which achieve sustainable development and lift people out of poverty. In an effort to alleviate poverty, it must be accompanied by economic growth, so that all kinds of risks that could adversely affect economic growth must be well managed, including those related to disaster risk and vulnerability in the development plan. This is because disaster can be a significant threat in achieving and sustaining development plans and objectives [11].

Based on the results of the review literature as described above, it can be seen that the risk management effectiveness factor in the oil and gas pipeline project is 3 (three) aspects of the main pillar of sustainable development system consisting of environmental, social and economic aspects, in addition there is one other important factor which is Disaster factors. For those, the four factors must be considered thoroughly and integrated at the design, construction and operational stages.

The method of analysis used in this study was conducted using AHP. To apply the AHP, in this case the stages are carried out in accordance with the stages arranged in the AHP method. The AHP stages are:

\section{Define the problem and determine the desired solution}

In many researches, it has been known that there are problems related to risk management application in oil and gas industry project which is not systematic and ineffective. Based on this, in this study will analyze how effective risk management application. From the results of the identification obtained variables in this study is divided into 3 (three) parts. namely:

a. Goal: Effectiveness of Risk Management

b. Criteria: Environment, social, economic and disaster factors

c. Sub Criteria: Design, construction and operational

2. Create a hierarchical structure that begins with the main purpose.

Variables that have been identified must be arranged in the hierarchy as can be seen in the figure 1 .

\section{Calculate the priority evaluation value}

After the hierarchy is composed, the next step is to calculate the priority evaluation value with create a pairwise comparison matrix that describes the relative contribution or influence of each element to the above-stated objectives or criteria, and calculate the eigenvalues and test their consistency.

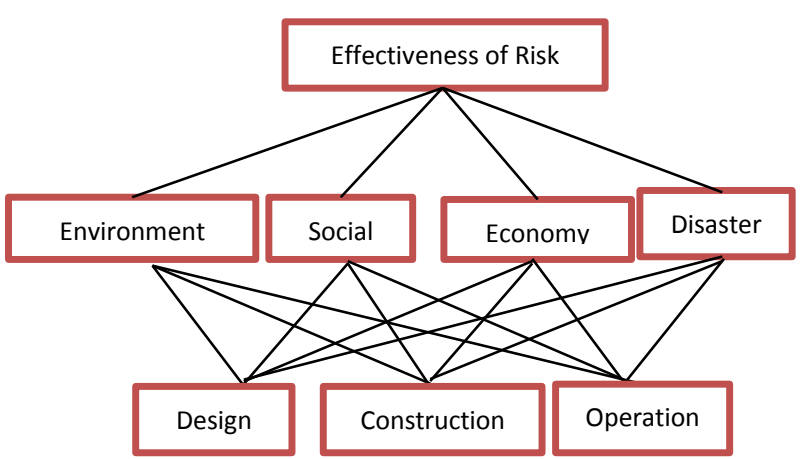

Figure 1. Structure of The Research Hierarchy 


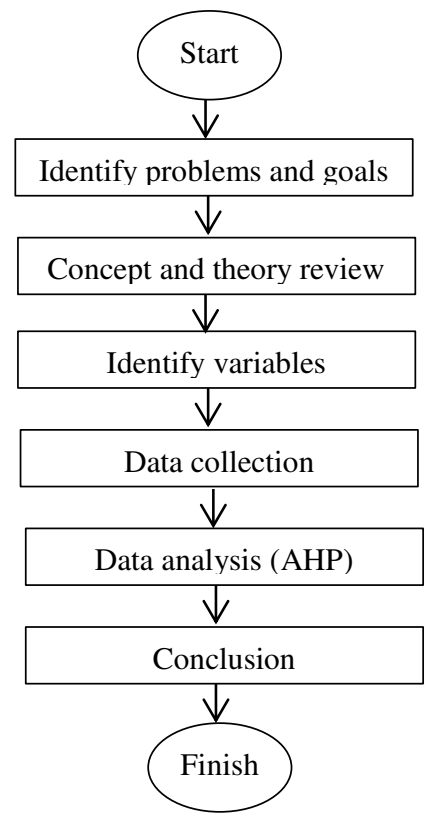

The calculation is operated on each questionnaire result obtained from each responder. After that, calculate the eigenvectors and check the consistency of the hierarchy.

\section{Calculate the priority Vector Evaluation Value of Factors}

After obtaining the priority value of the criteria to subcriteria calculation results, then further perform a calculation for Priority Vector Value.

The four factors in the three stages are then analyzed using Analytical Hierarchy Process (AHP). To obtain analytical data, these factors are arranged in a questionnaire and addressed to the Senior Pipeline Engineer and Senior Inspection Engineer. The data is then processed in the form of pairwise comparison of each criterion and sub criteria so that the weight of each factor and each stage of the project has been identified. The final step that must be done in the AHP stage is to check consistency, if the consistency value is $<10 \%$ then the research is considered consistent and can be accounted for. For the stages in the research can be seen in Figure 2

\section{METHOD}

The effectiveness of risk management in this study is reviewed from the literature review that the effectiveness of risk management can be seen from the concept of sustainable development. From the literature review results can be seen there are 4 (four) factors that must be considered in the application of risk management effectively at the design stage, construction stage and operational phase.

\section{RESULTS AND DISCUSSION}

\section{Data Analysis}

Figure 2. Flow Diagram of Research

The first step in the analysis using the ahp method is to collect data in pairs comparison based on the hierarchy that has been prepared as in figure 1. while the data input done in this research is based on the average result from the questionnaire. The first pairwise comparison is performed on the criteria stage. From the results of pairwise comparison in the criteria stage we can know the weight of environmental factors is $14 \%$, social factors is $40 \%$, economic factors is $15 \%$ and disaster factors is $31 \%$. The results are obtained based on the results of calculations in table 1 .

After computation of pairwise comparison and consistency check on criteria stage, then also done the same thing in sub criterion stage.

As for the calculation phases at the sub criteria stage can be seen in table 2 , table 3 , table 4 and table 5. While for the weighting results of each stage in sub criteria can be seen in table 6. From the table 6 it can be seen that the design weight of $57 \%$, Construction weight of $33 \%$ and operating weight of $10 \%$.

From the calculated weights obtained, it can be described in the hierarchy as can be seen in figure 3.

2. Sustainable development system and risk management effectiveness

The importance of risk management in the pursuit of sustainable development objectives encourages researchers to examine them with different methods. Al-Khalil et al (2005) developed the concept of risk management with the AHP (Analytic Hierarchy Process) method that can support the decision making system on the maintenance aspects of the oil and gas pipeline network so that the pipeline project can survive by taking into account the quality of pipes and environmental conditions [12]. Nielsen (2006) 
presents the concept of risk management in a pipeline project that not only deals with political and economic benefits but also on community needs and environmental conditions so as to achieve sustainable projects. The results of research conducted with theoretical statistical techniques show that risk management can be used comprehensively and effectively in project management to reduce the impact of emerging risks [4].

In the oil and gas pipeline project there is a dangerous failure so that required methods that can predict and failures that exist. Parvizsedghy and Zayed (2015), proposed a Neurofuzzy method that proved able to predict leak-related and explosive failures that impact on financial and environmental conditions. The method can be applied in the planning and maintenance phase. Failure in the pipeline project can also be caused by the theft of oil and gas through pipelines [13]. Therefore Hasan (2016) performs risk analysis using AHP (Analytic Hierarchy Process) which can support in decision system on aspect of improvement of pipeline network security and optimize security cost [2].

Based on the results of the previous research review as described above, the effectiveness of risk management in achieving sustainable construction projects can be done by integrating project risk, environmental risk and disaster risk.

\section{CONCLUSION}

From the results of the discussion has been known that from 4 (four factors identified, social factors have a weight of $40 \%$, then the second highest weight is the factor of disaster by $31 \%$, the third is the economic factor with the weight of $15 \%$ and the last is the environmental factor With a total weight of $14 \%$. Whereas at the sub-criteria stage it is known that the biggest weight lies in the design phase, which is $62 \%$, the second in the construction

stage with the weight of $26 \%$ and the lowest weight is at the operational stage, with weight of $12 \%$

The result is directly proportional to the toeri on sustainable development proposed by Abduh (2007), which mentions sustainable development as a development concept that aims to provide a better quality life for all people, both at present and also in generation in the future come [9]. So in this case social factors should be a priority in the design phase of the oil and gas pipeline project.

\section{ACKNOWLEDGMENTS}

The writers would like to express their appreciation to Ministry of Research, Technology and Higher Education of the Republic of Indonesia for providing various facilities for conducting this research.

\section{REFERENCES}

[1] A. K. Hossam and A. G. Hossam. "Review of pipeline integrity management practices." Int. J. Pressure Vessels Piping, 87 (7), 373-380. 2010.

[2] A. Hasan. "Security of Cross-Country Oil and Gas Pipelines: A Risk-Based Model". Journal of Pipeline Systems Engineering and Practice, (C) ASCE, ISSN 1949-1190. 2016.

[3] N.V Thuyet. S.O. Ogunlana and P.K. Dey. "Risk management in oil and gas construction projects in Vietnam". International Journal of Energy Sector Management. Vol. 1 No. 2, 2007. Hal. 175-194.2007 www.emeraldinsight.com/1750-6220.htm

[4] International Organization for Standardization (ISO). "ISO 13000:2009-Risk Management: Principles and Guidelines." Geneva

[5] K R. Nielsen . "Risk Management: Lessons from Six Continents". Journal of Management in Engineering, Vol. 22, No. 2, April 1, 2006. CASCE, ISSN 0742597X/2006/2-61-67/ \$25.00.

[6] G. Nyirenda and C.C. Ngwakwe. "Environmental management practices for sustainable development: agenda for harmonization". Journal of Environmental Economics, Volume 5, Issue 1, Pp. 76-85. 2014.

[7] Solusi P A. "Pipeline Integrity Management Systems Report". Jakarta: PT Transportasi Gas Indonesia. 2011

[8] Cintya, Y.A. (2014). "Implementasi Standar Internasional ISO 31000: 2009 Risk Management Principles and Guidelines di Sektor Energi - Minyak dan Gas".Crmsindonesia / knowledge / crmsarticles / implementasi - standar - internasional - iso - 31000 - 2009 - riskmanagement---principl

[9] Abduh, M. (2007). "Konstuksi Ramping Untuk Mencapai Konstruksi yang berkelanjutan”. Seminar Nasional; Sustainability Dalam Bidang Material, Rekayasa, dan Konstruksi Beton. Halaman 213 - 225

[10] Goh C S dan Rowlinson S. (2013). "Conceptual Maturity Model for Sustainable Construction". Journal of Legal Affairs and Dispute Resolution in Engineering and Construction, Vol. 5, No. 4, November 1, 2013. (c) ASCE, ISSN 19434162/2013/4-191-195/\$25.00.

[11] Bakhtiari, S. (2014). "Risk Management: A Powerful Instrument For Sustainable Development". OIDA International Journal of Sustainable Development. ISSN 1923-6654 (print) ISSN 19236662 (online). Pp 95 - 104.

[12] Al-Khalil M, Assaf S dan Al-Anazi F. (2005). "Risk-Based Maintenance Planning of CrossCountry Pipelines". Journal of Performance of Constructed Facilities, Vol. 19, No. 2, May 1, 2005. CASCE, ISSN 0887-3828/2005/2-124- 131/\$25.00.

[13] Parvizsedghy L dan Zayed T (2015). “Consequence of Failure: Neurofuzzy-Based Prediction Model for Gas Pipelines". Journal of Performance of Constructed Facilities, (C) ASCE, ISSN 08873828/04015073(10)/\$25.00 
Table 1. Pairwise Comparison and Calculate the Consistency Ratio of Criteria

\begin{tabular}{ccccc||c}
\hline Effectiveness of RM & Environment & Social & Economic & Disaster & Weight \\
\hline Environtment & 1 & $1 / 2$ & $1 / 2$ & $1 / 2$ & $14 \%$ \\
Social & 2 & 1 & 3 & 2 & $40 \%$ \\
Economic & 2 & $1 / 3$ & 1 & $1 / 4$ & $15 \%$ \\
Disaster & 2 & $1 / 2$ & 4 & 1 & $31 \%$ \\
\hline
\end{tabular}

Table 2. Pairwise Comparison and Calculate the Weighted Sum Vector of Environment to Sub Criteria

\begin{tabular}{cccc||c}
\hline ENVIRONMENT & Design & Construction & Operational & Weight \\
\hline Design & 1 & 2 & 6 & $55 \%$ \\
Construction & $1 / 2$ & 1 & 7 & $37 \%$ \\
Operational & $1 / 6$ & $1 / 7$ & 1 & $7 \%$ \\
\hline
\end{tabular}

Table 3. Pairwise Comparison and Calculate the Weighted Sum Vector of Social to Sub Criteria

\begin{tabular}{cccc||c}
\hline SOCIAL & Design & Construction & Operational & Weight \\
\hline Design & 1 & 2 & 4 & $53 \%$ \\
Construction & $1 / 2$ & 1 & 5 & $37 \%$ \\
Operational & $1 / 4$ & $1 / 5$ & 1 & $10 \%$ \\
\hline
\end{tabular}

Table 4. Pairwise Comparison and Calculate the Weighted Sum Vector of Economic to Sub Criteria

\begin{tabular}{cccc||c}
\hline ECONOMIC & Design & Construction & Operational & Weight \\
\hline Design & 1 & 7 & 6 & $75 \%$ \\
Construction & $1 / 7$ & 1 & 2 & $15 \%$ \\
Operational & $1 / 6$ & $1 / 2$ & 1 & $10 \%$ \\
\hline
\end{tabular}

Table 5. Pairwise Comparison and Calculate the Weighted Sum Vector of disaster to sub criteria

\begin{tabular}{cccc||c}
\hline DISASTER & Design & Construction & Operational & Weight \\
\hline Design & 1 & 3 & 7 & $53 \%$ \\
Construction & $1 / 3$ & 1 & 6 & $37 \%$ \\
Operational & $1 / 7$ & $1 / 6$ & 1 & $10 \%$ \\
\hline
\end{tabular}

Table 6. Calculate the Weighted of Sub Criteria

\begin{tabular}{ccccc||c}
\hline Factor & Environment & Social & Economic & Disaster & Weight \\
\hline Design & 0.08 & 0.21 & 0.12 & 0.16 & 0.57 \\
Construction & 0.05 & 0.15 & 0.02 & 0.11 & 0.33 \\
Operational & 0.01 & 0.04 & 0.02 & 0.03 & 0.10 \\
\hline
\end{tabular}




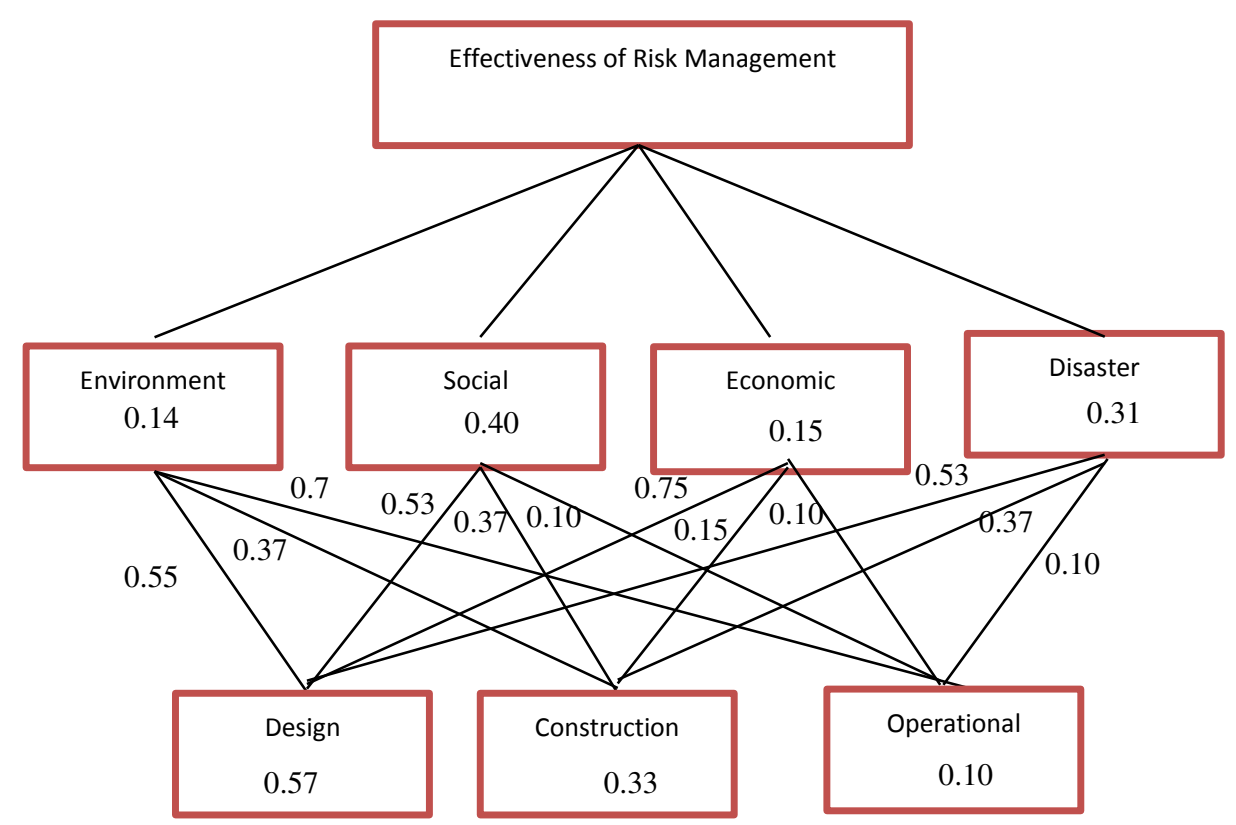

Figure 3. The Weight in The Hierarchical Structure 